\title{
Communal Marketplace Berbasis Koperasi sebagai Salah Satu Terobosan Inovasi bagi Pelaku Umkm Indonesia di Masa Pandemi Covid-19
}

\author{
Audito Aji Anugrah', Seno Aji Wahyono \\ ${ }^{12}$ Magister Manajemen Inovasi, Universitas Ma Chung, Villa Puncak Tidar Blok N No.1, Kab. Malang, \\ Jawa Timur, Indonesia, 65151 \\ Correspondence: Audito Aji Anugrah (132020001@student.machung.ac.id) \\ Received: 270721 - Revised: 280721 - Accepted: 280721 - Published: 280921
}

\begin{abstract}
Abstrak. Pandemi COVID-19 merupakan salah satu wabah yang khususnya memberikan dampak perekonomian bagi pelaku Usaha Mikro, Kecil dan Menengah. Adanya pembatasan aktivitas kegiatan ekonomi menyebabkan para pelaku Usaha Mikro Kecil dan Menengah kehilangan akses dalam memasarkan produknya. Solusi atas permasalahan tersebut dapat dijawab dengan melakukan promosi secara digital. Kegiatan Promosi Digital salah satunya adalah marketplace. Belajar dari marketplace arus utama dimana menggunakan sistem sharing economy dan teknologi peer to peer dalam proses bisnisnya. Melalui Artikel ini, akan mencoba mengeksplorasi bahwa dimasa pandemic COVID-19 para pelaku UMKM dapat membentuk sebuah marketplace kepemilikan bersama (communal marketplace) dengan mengadopsi teknologi dari marketplace arus utama. Namun tentunya dalam membentuk tersebut perlu peran kolaborasi antara pemerintah dan perguruan tinggi dalam menciptakan communal marketplace tersebut. Tentunya dalam menciptakan model bisnis tersebut terdapat tantang yang dihadapi dan harapannya dapat diaplikasikan dan dikembangkan melalui sebuah pilot project.
\end{abstract}

Kata kunci: Communal Marketplace, Small Medium Enterprise, Co-operations Model Bussiness, Innovation in COVID-19, Indonesia 
Citation Format: Anugrah, A.A., Wahyono, S.A,. (2020). Communal Marketplace Berbasis Koperasi sebagai Salah Satu Terobosan Inovasi bagi Pelaku Umkm Indonesia di Masa Pandemi Covid-19. Prosiding Seminar Nasional Abdimas Ma Chung (SENAM), 2020, 43-54. 


\section{PENDAHULUAN}

Usaha mikro, kecil dan menengah (UMKM) merupakan skala entitas usaha yang kini mendominasi dan menjadi tulang punggung di Indonesia. Menurut Undang-Undang Nomor 20 Tahun 2008 Tentang Usaha Mikro Kecil, dan Menengah bahwa UMKM adalah usaha yang dijalankan oleh perorangan, rumah tangga atau badan usaha kecil. Perekonomian Indonesia masih didominasi oleh Usaha Mikro, Kecil dan Menengah. UMKM Indonesia menyumbang hampir $97 \%$ dari pekerjaan domestic dan untuk 56\% dari total investasi bisnis. (OECD, 2018). Selama ini, UMKM telah memberikan kontribusi pada Produk Domestik Bruto (PBD) sebesar 57-60\% dan tingkat penyerapan tenaga kerja sekitar 97\% dari seluruh tenaga kerja nasional (LPPI Bank Indonesia,2015). Berdasarkan data dari Kementrian Koperasi dan UMKM (2019), menunjukkan bahwa di Indonesia terdapat Usaha Mikro sebesar 64.601.352, Usaha Kecil sebesar 798.679, dan Usaha Menengah sebesar 65.465.

Kini UMKM pun dihadapkan dengan sebuah fenomena Wabah Pandemi COVID-19 yang berdampak terhadap perekenomian. Fenomena tersebut menyebabkan Usaha Mikro dan Kecil dihadapkan dengan situasi lebih kompleks). Menurut Novianti (2020) Sektor yang paling terpuruk karena adanya Wabah Pandemi COVID-19 adalah UMKM, menyatakan bahwa terdapat sekitar 96\% UMKM yang mengalami dampak negatif pada bisnisnya dan 75\% diantaranya mengalami penurunan terhadap penjualan produknya. Sampai dengan saat ini UMKM masih belum bias mengatasi persoalan ini, Menurut Asmini et al (2020) UMKM sampai saat ini belum mampu mengatasi dampak pandemi COVID-19 karena penurunan permintaan dan menurunnya nilai transaksi masih dirasakan. UMKM kali ini dinyatakan tidak bisa menjadi penolong perputaran ekonomi Indonesia seperti di krisis tahun 1998 karena adanya pembatasan kegiatan masyarakat maupun operasional usaha.

Menteri Koperasi dan UKM Teten Masduki, menjelaskan bahwa UMKM memiliki peranan dan kontribusi yang sangat besar dalam perkenomian nasional. Dimana terdapat lebih dari 64 juta unit UMKM berkontribusi 97 persen terhadap total tenaga kerja dan 60 persen PDB nasional. Oleh sebab itu, jika UMKM mengalami dampak dari COVID-19 ini, hal ini tentu akan berdampak besar juga terhadap perekonomian nasional (Kementerian Koperasi dan UMKM, 2020). Sehingga, dalam penyelesaian ini perlu adanya peran pemerintah khususnya Kementrian Koperasi dan UKM dalam menjembatani persoalan tersebut. Menurut Hardilawati (2020) mengemukakan bahwa urgensi dan strategi yang dapat dilakukan oleh UMKM agar bertahan adalah dengan melakukan perdagangan secara online atau secara $e$-commerce, mulai melakukan promosi secara digital, serta menjalin dan 
mengoptimalkan hubungan pemasaran pelanggan. UMKM harus bereaksi dan beradaptasi dengan perubahan pasar karena mereka sebagian besar tidak bisa mendorong pasar.

Dalam mengahadapi situasi tersebut, Pemerintah dan UMKM sebagai pelaku bisnis memerlukan sebuah inovasi agar dapat tetap bertahan. Namun, dalam melakukan sebuah inovasi perlu adanya dorongan kolaborasi stakeholder (pemangku kepentingan) dalam menghadapi situasi yang kini dialami. Urgenitas UMKM untuk bertahan disaat pandemi COVID-19 yaitu memperkuat akses pemasaran dan peningkatan daya beli ini hanya dapat dijawab dengan melakukan sebuah langkah transformasi digital pada UMKM. Melalui artikel ini, maka penulis mencoba melakukan eksplorasi gagasan inovasi apa yang dapat diberikan kepada UMKM untuk menghadapi situsasi Pandemi COVID-19 dengan judul artikel ini penulis mencoba mengeksplorasi dengan judul jurnal Communal Marketplace

Berbasis Koperasi Sebagai Salah Satu Terobosan Inovasi Bagi Pelaku Umkm Indonesia Di Masa Pandemi Covid-19

\section{METODE PELAKSANAAN}

1. Belajar dari Layanan Marketplace dan Sharing economy arus utama yang berkembang saat ini

Langkah inovasi tersebut dapat dilakukan dengan adanya kolaborasi oleh para pemangku kepentingan untuk menghadapi situasi wabah Pandemi COVID-19 saat ini. Kementrian Koperasi dan UMKM sebagai salah satu otritas yang menangani para pelaku UMKM tersebut perlu menciptakan sebuah langkah inovasi khususnya untuk membantu para pelaku UMKM dengan membuat sebuah layanan marketplace dengan prinsip koperasi. Melihat urgenitas kebutuhan UMKM disaat Wabah tersebut adalah sebuah layanan akses pemasaran maka sebenarnya bersama-sama dapat belajar dari Marketplace yang saat ini berkembang yaitu Lazada, Shoppee, Tokopedia, Gofood (Gojek), Grabfood (Grab) dapat menjadi salah satu landmark dalam melakukan inovasi khususnya dalam layanan marketplace arus utama. Marketplace arus utama saat ini menggunakan teknologi platform digital berbasis peer to peer dan konsep dasar dari sharing economy sebagai mekanisme kerja dan core (inti) bisnisnya.

Marketplace merupakan sebuah pasar online yang mempertemukan penjual dan pembeli dengan tidak harus bertatap muka atau bertemu secara langsung. Menurut Opiida (2014) Marketplace adalah media online berbasis internet tempat melakukan kegiatan bisnis dan transaksi antara pembeli dan penjual. Pembeli dapat mencari supplier 
sebanyak mungkin dengan kriteria yang diinginkan, sehingga memperoleh sesuai harga pasar. Dalam aplikasinya yaitu menggunakan platform digital yang dapat mengakomodir adanya layanan pasar berbasis online tersebut menggunakan model peer to peer.

Gambar 1. Konsep Sharing Economy (Coorporate Finance Institute, 2021)

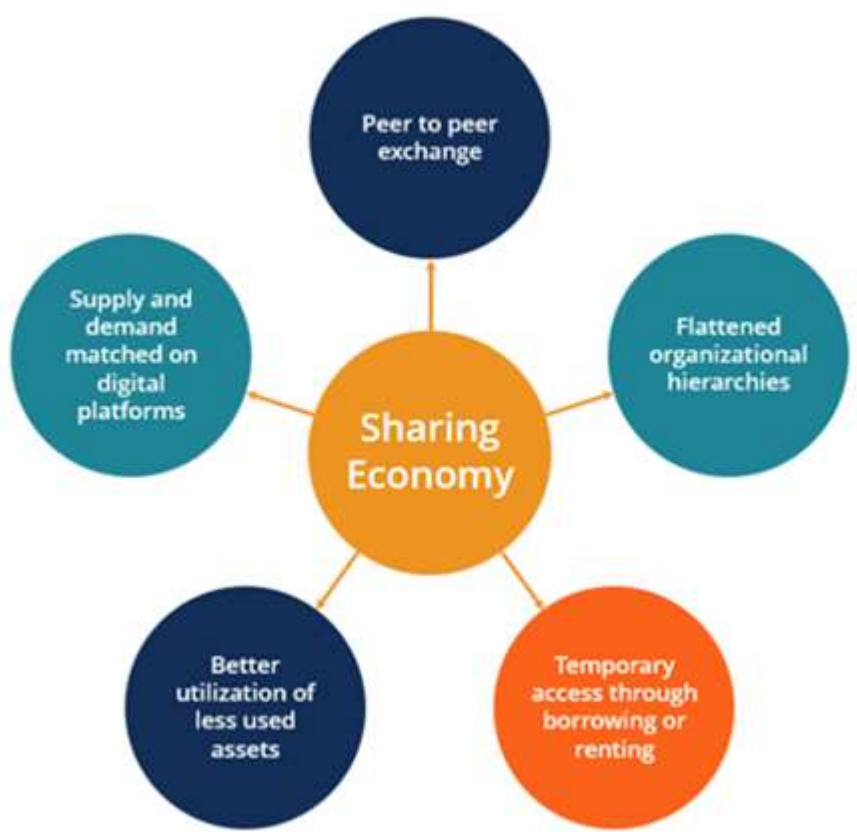

Sharing economy adalah sebuah model ekonomi yang di mana individu atau sekelompok orang mampu menghasilkan uang dari sumber daya yang dimiliki untuk memuaskan customer dengan memberikan jasa untuk individu atau sekelompok lainnya, melalui sebuah platform online (Turino, 2016). Konsep Sharing economy memiliki manfaat agar dapat memungkinkan orang dapat menggunakan sumber daya mereka (aset yang mereka miliki) secara lebih efisien. Semakin efisien dengan mereka memperoleh intensif yang lebih dalam keuangan dengan melakukan sharing economy ini. Selain itu juga dengan adanya sharing economy menjadikan sosial manusia menjadi lebih tinggi.

\section{Mengadopsi teknologi sharing economy untuk membangun ekosistem Koperasi} Digital bagi para Pelaku UMKM di masa Wabah Pandemi COVID-19

Osterwalder \& Pigneur (2010) mendefinisikan model bisnis adalah sebuah pemikiran yang menggambarkan tentang bagaimana sebuah organisasi melakukan tindakantindakan dalam menciptakan dan menawarkan nilai-nilai kepada pelanggan. Perspektif Model Sharing economy memiliki semangat nilai yang bersinggungan dengan Koperasi. 
Menurut Undang Undang Koperasi No 25 Tahun 1992 Tujuan koperasi sesuai yang tercantum pada pasal 3 yaitu: "Koperasi bertujuan memajukan kesejahteraan anggota pada khususnya dan masyarakat pada umumnya serta ikut membangun tatanan perekonomian nasional dalam rangka mewujudkan masyarakat yang maju, adil, dan makmur berlandaskan Pancasila dan Undang Undang Dasar 1945”. Model Sharing economy mencerminkan sistem dimana adanya kekuatan solidaritas dan partisipasi dalam menjalankan bisnisnya dengan mensharingkan alokasi sumber daya (resource) dan keuntungan melalui basis teknologi.

Tabel 1. Perbedaan Sharing Economy dan Koperasi (Data Diolah,2021)

\begin{tabular}{ccc}
\hline & Sharing economy & Koperasi \\
\hline Kepemilikan & Pemilik adalah Pembuat Akses & Pemilik adalah Anggota \\
Institusional & Layanan & (Membership) \\
Badan Hukum & Perusahaan Terbuka/ Perusahaan & Koperasi \\
Pengguna Jasa & Tebatas & Anggota (Prioritas) dan \\
Uaba Bersih yang & & Umum \\
dibagikan & Dividen Kepemilikan Saham & Surplus Hasil Usaha \\
& & dibagikan berdasarkan \\
& & kontribusi Anggota
\end{tabular}

Namun secara umum perspektif model sharing economy, tentunya sangat berbeda dengan prinsip koperasi. Sehingga dalam mengadopsi model sharing economy arus utama untuk membangun sebuah Koperasi Digital tersebut perlu adanya penyesuaian khususnya diselaraskan dengan Prinsip Koperasi. Koperasi merupakan organisasi ekonomi otonom, yang terbentuk karena adanya kelompok individu, bersatu untuk mendirikan koperasi. Dengan memperhatikan hal tersebut dapat dibedakan koperasi dengan bentuk usaha lain dari sisi keanggotaan adalah prinsip identitas ganda (dual identity), dimana anggota sebagai pemilik juga sebagai pelanggan dari koperasi. Status ini merupakan identitas anggota koperasi, dimana anggota sebagai pemilik identik dengan anggota sebagai pelanggan koperasi yang dituntut untuk memanfaatkan koperasi, hal ini akan berimplikasi luas terhadap perkembangan usaha koperasi melalui kegiatan-kegiatan yang dilakukan pada unit usahanya (Warsiati et al, 2020).

Pada tabel diatas secara proses bisnis antara sharing economy dengan koperasi memiliki perbedaan secara signifikan, Perbedaan tersebut tampak dari empat cakupan aspek 
yaitu Kepemilikan Institusional, Badan Hukum, Pengguna Jasa, dan Laba Bersih yang dibagikan. Tentunya model bisnis keduanya pun tidak sama dan berbeda. Adanya perbedaan model bisnis tersebut terdapat sebuah sistem yang dapat diadopsi oleh Koperasi dari Model Sharing economy yaitu penggunaan Teknologi Peer to peer. Adopsi Teknologi tersebut dapat menjadi sebuah gagasan dalam membangun sebuah marketplace diselaraskan sesuai dengan prinsip dan model bisnis dari koperasi.

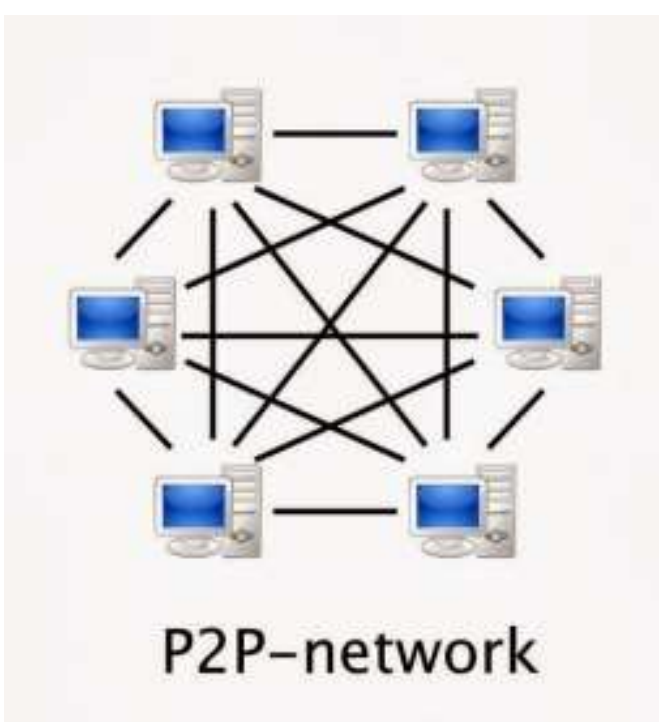

Gambar 2. P2P Network (Irul, 2021)

Model teknologi peer to peer adalah salah satu sarana proses digitalisasi model bisnis yang dijalankan dan sangat aplikatif diterapkan ke model bisnis manapun. Jaringan Peer to Peer (P2P) adalah Suatu model komunikasi dua arah antar pengguna PC melalui jaringan komputer atau Internet tanpa melalui sebuah server (idcloudhost,2021). Tentunya teknologi tersebut dapat menjadi salah satu adopsi untuk membangun koperasi bagi para UMKM dengan membentuk layanan marketplace dengan kepemilikan bersama (Communal Marketplace) sebagai salah satu terobosan inovasi dimasa Wabah Pandemi COVID-19.

\section{HASIL DAN PEMBAHASAN}

3. Gagasan Konseptual Communal Marketplace sebagai Terobosan Alternatif Inovasi Koperasi Berbasis Digital Bagi Pelaku UMKM Indonesia di masa Wabah Pandemi COVID-19 
Berkaca dengan Marketplace arus utama saat ini yang hanya menyediakan layanan teknologinya dan tentunya pemiliknya adalah yang memiliki layanan marketplace tersebut. Pada kesempatan ini sebenarnya koperasi dapat mengadopsi kekuatan teknologi tersebut dengan membuat ekosistem bisnis Marketplace Kepemilikan Bersama (Communal Marketplace). Communal Marketplace merupakan sebuah gagasan ide yang dapat dibangun untuk mengorgansir para pelaku UMKM untuk membentuk sebuah kepemilikan bersama layanan marketplace. Tentunya kepemilikan bersama layanan marketplace ini berdasarkan prinsip koperasi dengan sistem keanggotaan.

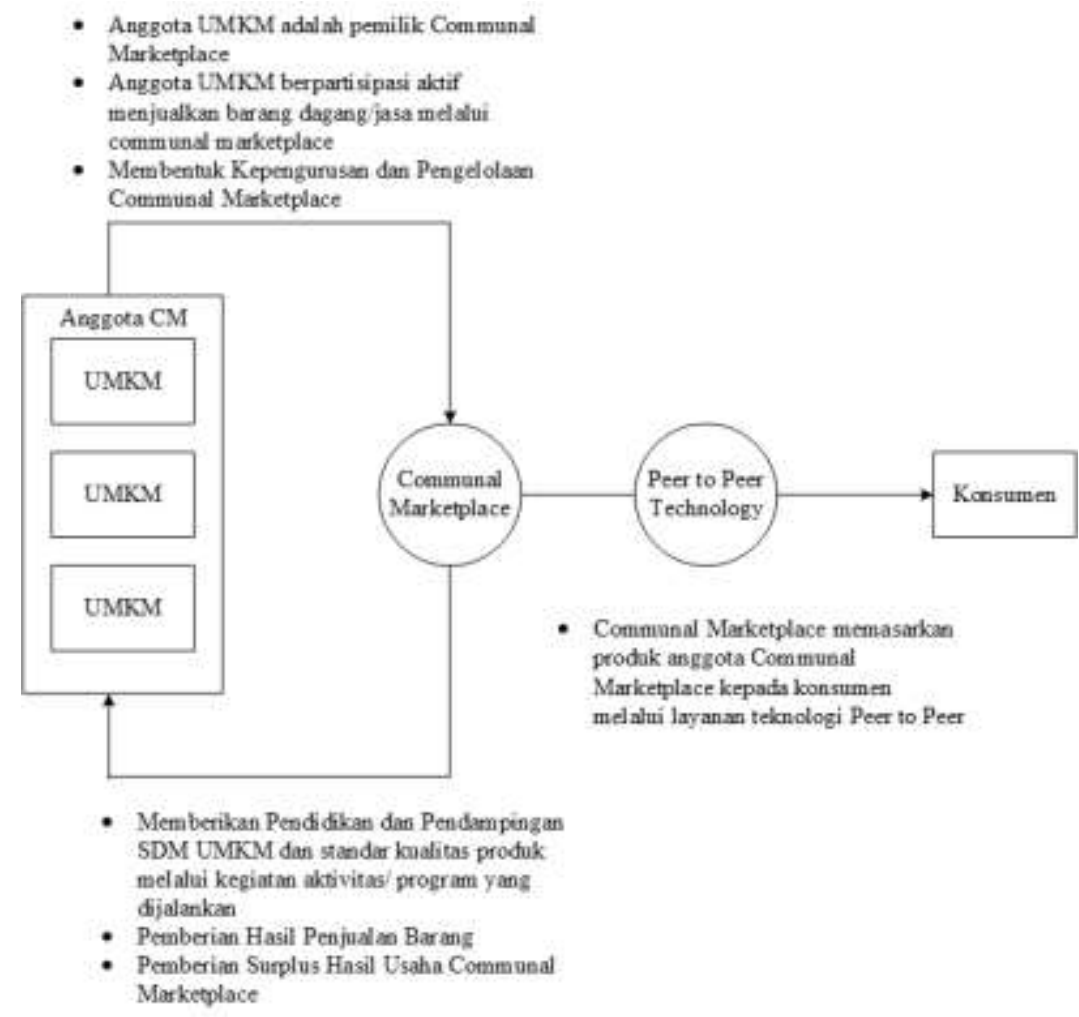

Gambar 2. Model Bisnis Marketplace Kepemilikan Bersama (Communal Marketplace) (Data Diolah,2021)

Pada gambar diatas menunjukkan sebuah gagasan dalam mengadopsi sistem pada marketplace arus utama yang berkembang saat ini diselaraskan dengan Prinsip Koperasi. Adanya peluang model bisnis tersebut bisa diterapkan dengan melihat peran mengorganisir para pelaku UMKM untuk membentuk sebuah Communal Marketplace dengan prinsip Koperasi sebagai salah satu penciptaan Koperasi digital bagi pelaku UMKM di Indonesia berbasis digital dan teknologi Peer to peer. Sehingga perlunya peran organisir para pelaku UMKM untuk dapat membentuk Communal Marketplace. 
Perbedaan secara signifikan dibandingkan dengan platform sharing economy pada umumnya seperti Lazada, Shoppe, dan Tokopedia yaitu antara lain proses sistem kepemilikan yang mana didalam sharing economy adalah penyedia jasa layanan tersebut dimiliki oleh penyedia tersebut, yang tergabung didalamnya hanya sebatas produsen dan konsumen. Namun pada model Communal Marketplace ini adalah sistem kepemilikannya yaitu berbasis anggota yaitu anggota UMKM. Didalam proses bisnis communal marketplace terdapat pemberian surplus hasil usaha dari laba bersih yang didapatkan oleh marketplace tersebut sesuai dengan kontribusi anggota. Hal tersebut tidak dimiliki oleh marketplace arus utama yang hanyak ada kegiatan aktivitas yaitu pemberian hasil penjualan barang.

Selain itu, adanya peran pendampingan SDM dan Kualitas produk ini agar mewujudkan UMKM memiliki kualitas produk yang dapat bersaing, peran pemberian pendampingan SDM dan Kualitas Produk ini dapat diakomodir melalui satu pintu. Selain itu esesnsi adanya Marketplace ini juga dapat memberikan kontribusi terhadap beberapa hambatan dan keterbatasan pada pelaku UMKM melalui sharing resource yang digunakan pada sharing economy. Sehingga hambatan dan keterbatasan yang dimilik UMKM tersebut terakomodir melalui layanan marketplace berbasis kepemilikan bersama tersebut.

\section{Tantangan Membangun Inovasi Koperasi Berbasis Digital untuk Para Pelaku UMKM}

Dalam Kondisi Wabah Pandemi COVID-19, UMKM pun harus dapat bertahan menghadapi perubahan yang akan datang. Untuk menghadapi beberapa tantangan yang ditimbulkan oleh lingkungan yang begitu dinamis melalui sebuah konsep baru studi bisnis model yang mana studi ini berorientasi praktis yang sedang popular dan meningkat (Zott et al, 2011). Pembentukan Communal Marketplace sebagai wujud Koperasi Digital perlu adanya keterlibatan pemerintah terkait peran mengorganisir para pelaku UMKM. Selain itu kolaborasi dengan Perguruan Tinggi dalam membuatkan sistem layanan peer to peer ini menjadi salah satu terobosan dimana peran dari Perguruan Tinggi ini dapat memperkuat terciptanya communal marketplace. Peran kolaborasi dan sinergitas pemerintah dan perguruan tinggi menjadi peran kunci dalam mewujudkan dan menyusun ekosistem untuk membentuk model bisnis Communal Marketplace.

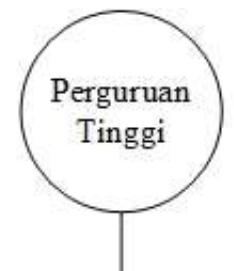

- Membuatkan sistem layanan Peer to Peer Marketplace

- Memberikan Pendampingan Sistem Layanan Peer to Peer 
Gambar 3. Proses keterlibatan peran Stakeholder Communal Marketplace (Data Diolah,2021)

Membangun sebuah inovasi Koperasi Berbasis Digital untuk Para Pelaku UMKM tersebut diperlukan sebuah intervensi secara khusus sekaligus menjadi sebuah tantangan bagi pemerintah untuk memberikan sentuhan inovasi terhadap UMKM dalam menghadapi situasi Wabah Pandemi COVID-19 tersebut dengan salah satunya membuat sebuah model bisnis dengan membangun Communal Ownership Marketplace dengan mengadopsi sistem teknologi yang digunakan oleh Marketplace Arus utama menggunakan Peer to peer Lending dan Sharing economy. Adapun tantangan tersebut antara lain

\section{Adanya kesenjangan digitalisasi di Indonesia.}

Adanya kesenjangan digitalisasi ini menjadi perhatian bagi pemerintah untuk memberikan pendidikan dan pendampingan bagi para pelaku UMKM. Berdasarkan hasil survey APJII tahun 2016, jumlah penetrasi pengguna internet di Indonesia mencapai 132,7 juta orang dengan 52,5\% adalah laki-laki dan 47,5\% adalah perempuan. Selain itu, Indonesia masih mengalami pemusatan pengguna internet di beberapa daerah, yaitu sebanyak 65\% atau 86,3 juta berasal dari pulau Jawa dan 15,7\% atau 20,7 juta berasal dari pulau Sumatera.

\section{Optimalisasi digital masih belum merata}

Berdasarkan hasil survey APJII tahun 2016 penetrasi pengguna internet berdasarkan usia juga cukup mengejutkan dengan 75,8\% diantaranya adalah mereka yang berusia 25 - 
34 tahun, disusul oleh usia 10-24 tahun sebanyak 75,5\%, lalu untuk usia 35-44 tahun sebanyak 54,7\%, usia 45-54 tahun sebanyak 17,2\%, dan $2 \%$ untuk usia 55 ke atas. Sehingga jika dilihat dan ditinjau masih banyak dominasi penggunaan (smartphone) digital dikalangan 24-54 Tahun. Namun, pada para pelaku UMKM rentan umur kebanyakan masih diatas 40 tahun keatas yang masih mencoba proses adaptif dengan teknologi

\section{Literasi digital bagi para pelaku UMKM belum merata}

Keberhasilan dan kesuksesan adanya penerapan marketplace tersebut salah satunya yaitu tingkat literasi digital dari pelaku UMKM tersebut. Optimalisasi digital khususnya penggunaan smartphone dalam melakukan aktivitas bisnis tentunya menjadi dasar kunci dalam menjalankan kegiatan bisnisnya. Perlunya pendampingan dalam hal penggunan teknologi kepada para pelaku UMKM agar dapat menambah kompetensi dalam penggunaan digital dan keperuntukannya

\section{Ragamnya Kompetensi Sumber Daya Manusia Pelaku UMKM}

Ragamnya latar berlakang pendidikan dan profesi dari para pelaku UMKM ini menjadi sebuah tantangan dalam melakukan peran pengorganisiran dan juga pemberian pendampingan kepada para pelaku UMKM. Dalam menjembatani hal tersebut diperlukan sebuah strategi khusus agar dapat memberikan pengorganisiran dan pendampingan bagi para pelaku UMKM.

\section{KESIMPULAN}

Di tengah Pandemi COVID-19 ini diperlukan sebuah langkah inovasi yang dapat dilakukan khususnya pada para pelaku UMKM. Keterbatasan akses akibat dari pembatasan aktivitas ekonomi ini menjadi salah satu penyebab utama UMKM mengalami penurunan pendapatan secara langsung. Belajar dari pengalaman marketplace arus utama saat ini, menggunakan peran teknologi peer to peer dan sharing economy sebagai salah satu inti bisnisnya dapat berkembang cukup pesat. Pemerintah terkait dalam hal ini Kementrian Koperasi berkolaborasi bersama dengan Perguruan Tinggi dapat menginisiasi adanya Marketplace berbasis kepemilikan bersama (communal marketplace) sebagai salah satu terobosan inovasi untuk membentuk koperasi digital Melalui eksplorasi gagasan ini dapat menjadi sebuah saran dalam mengembangkan proses inovasi untuk membangun koperasi digital bagi para pelaku UMKM. Adanya Wabah Pandemi COVID-19 ini menjadi salah satu tantangan untuk berinovasi dengan mengajak para pelaku UMKM untuk tetap bertahan. 
Adapun model bisnis ini dapat menjadi bahan pertimbangan untuk dieksplorasi lebih detail kedepannya dan dapat diaplikatifkan melalui sebuah pilot project

\section{UCAPAN TERIMA KASIH}

Ucapan terima kasih saya tujukan kepada teman-teman di salah satu gerakan koperasi kredit (Credit Union) di Kota Malang yangmana saya dapat diberi kesempatan untuk berkolaborasi, bertumbuh dan belajar bersama dalam membangun konseptual dalam pemecahan permasalahan bersama akibat dari Pandemi COVID-19 untuk para pelaku UMKM. Selain itu, saya ucapakan terima kasih kepada Para Dosen Magister Manajemen Inovasi yang telah memberikan wawasan pengetahuan mengenai teori inovasi.

\section{DAFTAR PUSTAKA}

APJII, A.P.PJ.I.I. (2016). Penetrasi dan Perilaku Pengguna Internet Indonesia 2016) (apjii.or.id)

Asmini, Sutama, I. Ny., Haryadi, W., \& Rachman, R. (2020). Manajemen Business Cycle Sebagai Peluang Usaha Pasca COVID-19 Suatu strategi Pemulihan Ekonomi Masyarakat. Indonesian Journal of Social Sciences and Humanities, 1(2), 121-129.

Coorporate Finance Institute. (2021). "What is Sharing Economy". https://corporatefinanceinstitute.com/resources/knowledge/other/sharing-economy/. (diakses pada tanggal 25 Juli 2021)

Hardilawati, Wan Laura., (2020). "Strategi Bertahan UMKM di Tengah Pandemi COVID19”. Jurnal Akuntansi \& Ekonomika. https://doi.org/10.37859/jae.v10i1.1934

Hudson Smith, M., \& Smith, D. (2007). Implementing production/operations management practices and performance.International Journal of Production Economics, 106(2), 393-408. https://doi.org/10.1016/j.ijpe.2006.07.011.

Idcloudhost. (2021). https://idcloudhost.com/kamus-hosting/peer-to-peer/ . (diakses pada tanggal 25 Juli 2021)

Irul. M. (2021). "Pengertian dan Tipe Jaringan Komputer". http://www.isrul.com/2016/07/pengertian-dan-tipe-jaringan-komputer.html. (diakses pada tanggal 25 Juli 2021).

Kementrian Koperasi dan UKM.(2019).Data UMKM

Kemenkop.(2020).https://kemenkopukm.go.id/read/sektor-umkm-jadi-kunci-pemulihanekonomi-di-tengah-pandemi. (diakses pada tanggal 25 Juli 2021)

LPPI, Bank Indonesia. (2015). Profil Bisnis Usaha Mikro, Kecil dan Menengah (UMKM). Jakarta.

Nofianti, L. (2020). Solusi UMKM di New Normal. https://uinsuska.ac.id/2020/06/16/solusi-umkmdi-new-normal/ (diakses pada tanggal 25 Juli 2021)

OECD. (2018). SME and Entrepreneurship Policy in Indonesia 2018. https://doi.org/10.1504/ijc.2017.1000564

Opiida. (2014) Pengertian E-marketplace. Retrieved from https://tokohalista.wordpress.com (25 Juli 2021).

Osterwalder, A dan Pigneur, Y. (2010). Business Model Generation : A Handbook for Visionaries, Game Changers dan Challangers. New Jersey : John Wiley \& Sons, Inc.

Tirto.id. (2020). Moody's Prediksi Ekonomi Indonesia Melambat di 4,8\% Akibat Corona", 
9 Maret 2020, https://tirto.id/moodysprediksi-ekonomi-indonesiamelambat-di-48akibat-coronaeDPW, diakses 9 Maret 2020.

Turino, H. (2016). Meretas Konsep Ekonomi Berbagi. Tangerang Selatan: PT. Kusuma Putra Kreatif.

Undang Undang Koperasi No 25 Tahun 1992.(1992). Tentang Perkoperasian

Undang-Undang Nomor 20 Tahun 2008.(2008). Tentang Usaha Mikro Kecil dan Menengah

Yusup, J. (2017). Analisis Perumusan Dan Penerapan Sistem Akuntansi Pada Usaha Kecil Menengah (Studi Kasus Ukm Bakso Pejagan). Syntax Literate; Jurnal Ilmiah Indonesia, 2(11), 76-90.

Warsiti, Wiwi., Sudartono, Tiris \& Dewi, Riana. (2020). Peranan Koperasi Sebagai Bentuk Implementasi Ekonomi Pancasila di Era Digital. Jurnal : Empowerment in the Community Vol. 1, No. 1, Februari 2020

Zott, C., Amit, R., \& Massa, L. (2011). The business model: Recent developments and future research. Journal of Management,37(4), 1019-1042.

https://doi.org/10.1177/0149206311406265

(C) 2021 by authors. Content on this article is licensed under a Creative Commons Attribution 4.0 International license. (http://creativecommons.org/licenses/by/4.0/). 